\title{
ОСНОВАНИЯ КОМПОЗИТНОЙ И СЛОВОСОЧЕТАТЕЛЬНОЙ НОМИНАЦИИ
}

Статья посвящена рассмотрению механизмов образования словосочетательной номинации и композитной номинации растений. Данное изучение актуально, поскольку в теоретических работах установлены внешние (акцентно-графические, дистрибутивно-валентные, структурно-номинативные) свойства именных словосочетаний и именных композитов-флоронимов. Исследован внешний ономасиологический срез номинации флоронимической действительности. Однако существует внутренний срез номинации, представленный положениями о логико-семантической соразмерности и объема содержания определяющего и определяемого компонентов сложноструктурного образования. Компонентный состав такого образования репрезентируется в терминах логических бинарных оппозиций гипонимов и гиперонимов.

Словосочетательная прямая объемная номинация терминологических словосочетаний-флоронимов дости- гается посредством самодостаточности номинативных свойств их компонентов без привлечения дефиниционной информации.

Напротив, композитная номинация объектов растительного мира является непрямой или косвенной в эндоцентрических композитах. Номинативная самодостаточность компонентов эндокомпозита достигается не только объемом их соразмерности, но и за счет релевантной информации отсылочной части дефиниции. Первые модификаторные компоненты, как правило, эксплицируются посредством явлений падежной семантики (непрямая номинация) или метафорически (косвенная номинация) Композитная номинация в экзокомпозитах-флоронимах является полностью косвеннономинативной. Самодостаточность достигается исключительно за счет развернутой релевантной информации словарной дефиниции

Ключевые слова: номинация, словосочетание, композит, соразмерность, содержание, дефиниция.

\section{O. Ryabko}

\section{THE FUNDAMENTALS OF WORD-COMPOUND AND COMPOSITE NOMINATION}

The article focuses on the study of the mechanisms that create nomination of wordcombinations and nomination of composites on the material of compound structured formations in flora namings. This study is relevant, because in theoretical works external (accent-graphical, distributive - valent, structural-morphological) properties of nominative flora wordcombinations and nominative flora composites have been considered. External onomasiological presentation of flora surroundings have been thoroughly studied.

But there is internal presentation of nomination which is explained by the aspects of logic-semantic codimension and semantic volume of a defining component and a defined component in compound structured formation. Components content of such a formation is represented in terms of logical binary oppositions of hyponyms and hyperonyms. Direct volume nomination of wordcombinations is archieved by codimension of nominative properties of their components without definition information

В лингвистическом знании большое значение имеет изучение когнитивных аспектов развития общеязыковой теории номинации и терминологической номинации. Гуманитарные, естественно-научные, технические дисциплины инновационные технологии продуцируют энциклопедический исследовательский материал в сферу терминоведения. Процессы конвенциализации и повышение частотности словоупотреблений в конкретных профессиональных сферах
On the contrary, composite nomination of plants' objects of the world is both non-direct and indirect in endocentric composites. Nominative codimension of components in endocentric composites is achieved not only by the volume of their codimension, but also by the relevant information of the initial elements in the definition. The first modified components, as a rule, are explicited by the phenomena of case semantics (non-direct nomination) and by metaphors (indirect nomination)

Composite nomination in exocentric composites of flora namings is wholly indirect from nominative viewpoint. Codimension of implicitly expressed modified component and basic component is achieved exclusively by the extensive relevant information of vocabulary definition.

Key words: nomination; wordcombination; composite codimension; content; definition.

человеческой деятельности способствуют переходу различных номенов из разряда пред-, квази- и псевдотерминов в пласт терминологической лексики. Изучение языковых особенностей терминополей и номенклатур приобретает особую актуальность в свете современных параллельно протекающих процессов специализации отраслей и унификации некоторых междисциплинарных сфер профессиональной активности. Детальный анализ интра- и экстра-полевых характеристик 
терминополя флоронимов вносит значительный вклад в когнитивную теорию мотивационно-деривационной номинации [5].

В фокусе нашего теоретического рассмотрения находится лексико-номинативное поле наименований растений английского языка (флоронимы), представленное сложноструктурными образованиями (именными композитами и именными словосочетаниями). Репрезентативный фактологический материал, характеризуя научную и наивную флоронимическую картину мира, систематизирован в авторском «Англо-латинско-русском ботаническом словаре», скрупулёзно классифицируя данную область знания [6].

Как известно, ботанические и зоологические наименования с точки зрения содержательного состава терминологии подразделяются на научно-когнитивные системы (термины) и обыденно-когнитивные системы (номенкпатуры) природных реалий национальных языков. При этом следует подчеркнуть лингвокультурную детерминированность как единичных теминов, так и деривационных моделей образования сложных терминологических конструкций, что базируется не только на особенностях представления языковой системой потенций вербализации ментальных образов специального и научного знания, но и на экстралингвистических факторах, в первую очередь тех или иных ареально-топологических спецификациях, обусловливающих наличие видового разнообразия фолоры конкретного региона. Данное положение четко прослеживается на материале флоронимов, определяя их место в системе научно-когнитивной и обыденно-когнитивной номинации [2]. В сопоставительном плане научно-когнитивная номинация является продуктом научно-эмпирического познания действительности, её принципы однородны и единообразны. Обыденно-когнитивная номинация определяется фактором чувственного восприятия и архетипическими формами сознания номинатора.

Изучив внешне-номинативные свойства сложноструктурных флоронимических образований на основе английского языка, представленных в наиболее авторитетных лексикографических источниках, можем утверждать, что терминологические именные словосочетания относятся к научно-когнитивной номинации, и представлены прямой объемной словосочетательной номинацией, а композиты относятся к обыденно-когнитивной номинации и представлены непрямой / косвенной композитной номинацией.

Основные типы номинации (первичная и вторичная; прямая и непрямая / косвенная) действуют на материале различных номинативных полей, в том числе и в номинативном поле структурных образований-флоронимов. Логико-семантический тип косвенной номинации определяет функционирование композитов (эндоцентрических и экзоцентрических). При изучении номинативной природы сложноструктурных наименований используются концептуальные данные теории определённых / неопределённых дескрипций, теории ресреренции, теории самодостаточности / несамодостаточности [3, с. 10].

Словосочетательная номинация объектов флоры является прямой, при которой однозначно осуществляется контекстно-свободная идентификация реалий растительного мира, в основном, через их гиперонимное представление или гипонимное номинирование на соответствующих уровнях коммуникации. Именно подобный тип номинирования способствует наиболее точной и однозначной вербализации рефлексии над объектами реального мира флоры и обеспечивает адекватную эмпирическую верификацию генерализованного содержания терминоединиц. Терминологическое флоронимическое наименование не содержит элементов переосмысления, семантической деривации. Их целостная самодостаточность достигается компонентной сочетаемостью без привлечения дополнительной информации (атрибутивный / модификаторный компонент + опорный компонент = эксплицитно выраженное номинативное значение терминологического фолронимического словосочетания). Интерпретация компонентов именного словосочетания флоронимов анализируется на их гипонимных / гиперонимных свойствах, в связи с чем особенно возрастает интерес к изучению прямой номинации.

Расклассифицированный фактологический материал позволил выделить три комбинационных варианта гипонимов и гиперонимов в составе словосочетательной номинации именных флоронимических образований, а именно, гипоним гипоним; гипероним :.. гипоним; гипоним :.. гипероним. Приведём соответствующие дефиниционные примеры из Большого Оксфордского словаря, который на настоящий момент является наиболее авторитетным лексикографическим источником. Первая вариативная группа гипоним гипоним является наиболее репрезентативной, определяя терминологические флоронимические сочетания, например, corn mint - мята полевая; grape hyacinth - гиацинт кистичный; rose mallowалтей розовый; lemon thyme - тмин лимонный saffron pear - груша шафрановая и многие другие.

Первые гипонимные компоненты обладают однозначной самодостаточной инорормацией для выявления, и, в конечном итоге, для номинирования терминологического словосочетания. Отличительной характеристикой является то, что первые гипонимные компоненты словосочетания способны к образованию пропорциональных оппозиций. Данное языковое явление мы определяем как подвидовые условия реализации экстралингвистических феноменов действительности. Ещё более репрезентативным предстаёт признаковое наполнение вторых гипонимных компонентов терминологического словосочетания. При целостном словосочетательном номинировании дополнительная мотивационно-номинативная информация, передаваемая первым гипонимным компонентом, функционирует исключительно с точки зрения уточнения / дифференциации определяемого гипонимного компонента. 
Проиллюстрируем данное положение на конкретных примерах, изъятых из толкового словаря «The Oxford English Dictionary». В дефиниции словосочетания «beaked parsley» представлена градуальная релевантная информация. Во-первых дефиниционная информация о гипонимном опорном компоненте - parsley «a biennial umbelliferous plant Petroselium satrivum, a native of Mediterranean region, having white flowers and aromatic leaves which in the commonly cultivated variety are finely divided and curled and are used for seasoning and garnishing various dishes) in another variety the large spindle-shaped root (Hamburg parsley), which is dressed and eaten" [11]. Во-вторых, представлена одномерная информация о терминологическом словосочетании - beaked parsley - «the genus Anthriscus from its beaked fruit» [11]

В словосочетательной номинации рассмотренного образования функция первого гипонимного компонента сузилась до определения его как подвидового терминологического словосочетания В аналогичных примерах чётко прослеживается установленная корреляция между определяющим и определяемым гипонимами терминологического фллоронимического словосочетания, например, pine «a tree of the genus Pinus, mostly of large size with evergreen leaves of which many speices afford valuable timber, turpentine and some have edible seeds» [11]; sugar pine «Pinus Lamertiana of California, which yields a sweet resin used for sugar» [11]. Дополнительный пример образования подвидового словосочетательного номинирования реалий растительного мира, poplar «a tree of the genus Populus, comprising large trees of rapid growth" [11] и soft poplar "Poplar grandidentata of North America with soft wood, which is used for paper-making» [11]. Таким образом, сочетание первых и вторых гипонимных компонентов в словосочетательной флоронимической номинации позволяет образовать флоронимическое словосочетание на основании логико-семантической соразмерности их компонентов [8].

Вторая вариативная группа гипероним :: гипоним менее репрезентативна в количественном отношении, например, herb aloe - чистоуст величавый; tree mallow - хатьма древовидная; shrub trefoil - вязовник; nut pine - сосна кедровидная; wood germander - дубровник шалфейный. Следует отметить, что гиперонимные первые компоненты обладают значительной степенью абстракции, но меньшим идентифицирующим потенциалом подвидовой конкретизации терминообразования. Второй гипонимный компонент выполняет идентифицирующую функцию подвидового значения к которому стремится и первый гиперонимный компонент терминологического словосочетания, имея способность к созданию оппозиций, как например, currant «small round berry of certain species of Ribes: Ribes nigrum (black currant)»: Ribes rubrum (red currant). В отличие от первой вариативной группы корреляции, во второй группе не наблюдается равноценное компонентное участие в словосочетательной номинации, поскольку идентифицирующую преференцию имеет второй гипонимный компонент.

Третья вариативная группа гипоним :: гипероним в словосочетательной флоронимической номинации имеет место только в тех случаях, когда второй гиперонимный компонент сочетается с первым гипонимным компонентом с «замковым» значением - географические и локативные признаковые наименования [7]. Эти характерные признаковые компоненты являются семантически настолько репрезентативными, что могут определяться как самодостаточные признаки для логико-семантической соразмерности компонентов терминологического словосочетания.

На первом месте оказываются терминологические флоронимические словосочетания с первым гипонимным компонентом в функции дескриптора, представленном географическими наименованиями, например, Himalayan pine - сосна гималайская, Aleppo pine - сосна Аллепская, Iceland moss - исландский мox, Bermuda cedar - можжевельник бермудский, Kaffir corn - сорго кафрское и многие другие примеры. На втором месте находятся терминологические флоронимические словосочетания, где первый гипонимный компонент представлен локативными / природными наименованиями, например, sea trefoil-глаукс морской, rock oak - дуб горный, marsh tea - багульник болотный, mountain savory - чабер горный и другие.

Последующие позиции занимают словосочетания - флоронимы, у которых в номинативном процессе первые гипонимные / дескриптивные компоненты представлены, в порядке убывающей репрезентативности, референтными наименованиями: «артефакты» например, treacle mustard горчица; globe daisy - глобулярия; «продукты питания», например, butter daisy - лютик едкий; sugar cane - сахарный тростник; «части тела человека», например, фасоль обыкновенная; nipple cactus - мамиллярия миссурийская; «природные явления», например, moon daisy - маргаритка светлая; star hyacinth - пролеска прелестная.

Таким образом, важнейшим семантико-номинативным критерием словосочетательной номинации является соблюдение соответствия между объемным, эксплицитно выраженным, признаковым наполнением первого компонента и видовым / подвидовым опорным компонентом. Паритетное представление идентифицирующих свойств определяющих и определяемых оценивается в оппозиционных бинарных соотношениях гиперонимных / гипонимных терминах

В отличии от словосочетательной номинации, композитная номинация объектов флоры является косвенной, при которой осуществляется контекстно-связанная идентификация реалий растительного мира, которая используется как средство номинативной референции в условиях неналичной речевой коммуникации. Композитные флоронимические наименования представлены эндокомпозитами и экзокомпозитами. В эндоцентрических копозитах принцип соразмерности определяющего и определяемого не 
имеет места, что свидетельствует об отсутствии паритетности между определяемым и определяющим компонентами, характеризуется номинативными основаниями непрямой и косвенной номинаций. Соответствующая паритетность / межкомпонентная самодостаточность эндокомпозитов осуществляется за счёт их дефиниционной информации отсылочной части композита (эксплицитно выраженный атрибут / модификатор + дефиниционная информация отсылочной части эндокомпозита) [3]. Приводимые дефиниционные примеры свидетельствуют о том, что без дефиниционной информации невозможно достичь идентифицурующее значение эндокомпозита, например, Danewort «the plant so named in accordance with a popular notion that it sprang up in places where Danes slaughtered Englishmen or where slaughtered by them» [11]; devil-wood «a small North American tree with wood of extraordinary thoughness and heaviness» [11]; dagger-plant «a plant of the genus Jucca having sharp-edged and pointed leaves" [11]. В основании косвенной композитной номинации, представленной метафоризованными модификаторами, находится образное, ассоциативное мышление в рамках когнитивного / чувственного восприятия объектов растительного мира. Оппозиционно в прямой объемной словосочетательной номинации присутствуют элементы дискурсивно-логического мышления номинаторов, связывающих индивидуально-ассоциативные компоненты, лежащие в основе метафорического переноса, для адекватной экспликации ментального образа сферы источника с актуализированными компонентами сферы мишени.

В процессе композитного номинирования объектов растительного мира введение категории ассоциативного потенциала номинативного поля позволяет установить корреляцию между его модификаторными именами и набором экстралингвистических признаков. Этот набор порождается каждым номинативным полем благодаря механизмам транспонируемой семантики (метафоризация и падежная семантика, осуществляющиеся большей частью на основе сдвигов в семантических полях). В основе явления косвенно-номинативной транспонируемости лежит механизм метафоризации. Изучив признаковую семантику первых компонентов, эндокомпозитов удалось выделить значительное количество признаков (18 дескрипторных наименований) экстралингвистических реалий.

Свыше $60 \%$ признаков образованы на основе механизма метафоризации. Приведем соответствующие примеры эндокомпозитов флоронимов, где опорный компонент представлен гиперонимным компонентом, а первый компонент имеет метафоризованное признаковое значение «фрормы», (цвета», «запаха», «манеры роста» и ряда других значений: umbrella tree cone of a variety of trees, whose leaves and habit of growing resemble an umbrella» [11]; swan-plant «an orchid having flowers with a long curved column like a swan neck»
[11]; tiger-flower «a genus of tropical American plants bearing purple, yellow or white spotted flowers» [11]: camel's hay "a sweet-scented grass growing in the East» [11]; jointweed "a name of different weeds having conspicuously jointed stems» [11]; lungwort «the plant having leaves with white spots, fancied to resemble the spots in a diseased lung" [11].

В основе непрямономинативной транспонируемости находится механизм падежной семантики [9]. При анализе признаковой семантики первых компонентов эндокомпозитов фллоронимов отмечаем ассоциации номинаторов, связанные с природными местами произрастания флоронимов, ассоциации, связанные с осознанием целевого назначения растений, ассоциативные маркеры природного темпоратива. Приведём соответствующие примеры локативного признака, sand-grass «any species of grass which grows in sand and serves the purpose of a sand-binder» [11]; pondweed «an aquatic herb that grows in ponds and still waters» [11]; corn-flower "a name given to various plants commonly growing amongst corn» [11].

Абсолютное большинство примеров характеризует признаки целевого назначения и использования растений, что объясняется предметно-деятельностными актами и антропоцентрическим вектором в освоении объективной реальности человеком, представленных в первых модификаторных компонентах эндокомпозитов-флоронимов, например с объектно-целевым назначением широкого спектра практической деятельности (продукты питания, лекарства, фураж), tea-tree «а shrub or low tree, the dried leaves of which form the tea of commerce» [11]; sugar-beet «any variety of the beetroot plant from which sugar is manufactured» [11] honey-plant «a plant yielding nectar» [11]; ear-wort «a plant supposed to be good for curing deafness» [11]; throat-wort «the third sort of Cantebury Bells called throat-wort of its virtue in curing the diseases of throat» [11]; clearing-nut "a tree-fruit used by the Indians to clean muddy water for use» [11]; rye-grass "several species of grass extensively cultivated as forage and fodder grasses» [11].

При помощи падежной семантики первые компоненты эндокомпозитов со структурой NN трансформируются и в маркеры качественных признаков, например, cottonwood «the name of several species of poplar, so-called from the cottonlike substance surrounding the seeds") [11]; thorntree «a tree having or bearing thorns» [11], наряду с маркерами темпоративных признаков, которые выражаются косвенно-номинативно через наименования религиозных праздников, обычаев, лиц и религиозных деятелей. Приведём соответствующие примеры, St. Michael pear «a kind of pear that is ripe at Michaelmas, Michael - the name of one of the Archangels, the feast at St. Michaels is on the 29th of September» [11]; Christmas rose «a species of Hellebore, with large white flowers, commonly cultivated in gardens and is in bloom from December to February") [11].

При экзокомпозитном номинированни объектов фрлоры действует механизм метафоризации 
имплицитно выраженных первых и вторых компонентов экзокомпозита, наряду с частично использованным механизмом падежной семантики. С помощью этих механизмов транспонируемой семантики достигается идентификация денотативного значения экзокомпозита. Номинативная паритетность / самодостаточность компонентов экзокомпозитов-флоронимов осуществляется исключительно с помощью релевантной дефиниционной информации, что определяет полный косвеннономинативный характер означивания флоронимических видовых реалий. Приведём дефиниционные примеры экзокомпозитной номинации, где метафоризованы оба компонента композита, например, snake-head «the North American plant, Chelone glabra, with flowers shaped much like the head of a snake» [11]; hen's-foot "the name given to two different plants from the resemblance of the divided leaves to a hen's claws» [11]; short-neck «a variety of pear, having a rounded form, so called from the shortness of its form and tail» [11].

Падежно-семантическая транспонируемость компонентов экзокомпозитной номинации в аспекте теории 4. Филлмора [11] представлена моделями цели, инструмента, природного локатива и темпоратива. Приведём дефиниционные примеры в последовательности указанных моделей, например, self-heal «a name for various plants believed to have great healing properties, e.g self-heal is good to heal great wounds) [11]; wakerobin «the plant Arum maculatum, the root of which is purgative and penetrating, so they prepare a powder of it, that is used in astma's dropsy and hypocondriac melancholy" [11]; allgood "the herb Chenopodium which grows about ways and paths and by hedges»)
[11]; long-lasters «they are apples, so called from their durableness, continuing two years before they perish» [11].

С учетом когнитивно-мотивационного критерия, который представляется базовым для английской лингвокультуры, сложные терминологические номены условно распадаются на три деривационно-тематические группы: локативно-темпоративную (наименее представленную в частотном плане, формирующую периферийную область номинирования), прагматическую (более широко представленную и образующую ближнюю перифферию фрлоронимического терминополя) и параметрическую (наиболее широко представленную, единицы которой составляют ядерную область терминодеривации). Подобное распределение мотивационно-деривационных компонентов в терминополе флоронимов базируется на перцептивных как наиболее архетипических и аксиологических как основанных на эмпирическом опыте и ассоциативной рефлексии механизмах восприятия объективной реальности и оценки отдельных представителей растительного мира в понятиях «вред / польза», «распространенность / уникальность» и т.п.

Представленные в статье два направления номинирования сложноструктурных флоронимических образований - словосочетательная номинация и композитная номинация имеют различные механизмы номинации / номинативные основания. К таким основаниям относятся явления прямой словосочетательной номинации, непрямой / косвенной эндоцентрической номинации и полнокосвенной экзоцентрической номинации объектов флоры.

\section{Литература}

1. Кравченко А. В. Язык и восприятие. Когнитивные аспекты языковой категоризации. Иркутск: Иркутский университет, 1996. $160 \mathrm{c}$.

2. Кубрякова Е. С. О связях когнитивной науки с семиотикой (определение интерпретации знака) // Язык и культура. Факты и ценности. М.: Языки славянской культуры, 2001. С. 283-291.

3. Кубрякова Е. С. Части речи в ономасиологическом освещении. М.: Наука, 1978. 114 с.

4. Позднякова Е. М. Категория имени деятеля и пути ее синхронного развития в когнитивном и номинативном аспекте: на материале английского языка: дисс. ... д-ра филол. наук. М., 1999. 318 с

5. Рахилина Е. В. Когнитивный анализ предметных имен: от сочетаемости к семантике: автореф. дис. ... д-ра филол. наук. М., 1999. 41 с.

6. Рябко О.П. Англо-латинско-русский ботанический словарь. Ростов-на-Дону: РГУ, 1996, 663 с

7. Рябко О. П. Пространственно-временной континуум объекта когнитивных процессов номинации // Весник Волгоградского государственного университета. Серия 2. Языкознание. 2016. Т.15. №4. С.190-196.

8. Филлмор Ч. Основные проблемы лексической семантики // Новое в зарубежной лингвистике. 1983. Вып. 11 C. $74-112$.

9. Fillmore Ch. J. The Case for Case // Universals in Linguistics theory / ed. E. Bach, R. Harns. L., 1968. P. 1-88

10. The Oxford English Dictionary. URL: https://www.oxforddictionaries.com/. (Accessed: 21.09.2019).

\section{References}

1. Kravchenko A. V. Yazyk i vospriyatie. Kognitivnye aspekty yazykovoi kategorizatsii (The language and perception Cognitive aspects of language categorization). Irkutsk: Publishing House of Irkutsk University, 1996. 160 p. (In Russian)

2. Kubryakova E. S. O svyazyakh kognitivnoi nauki s semiotikoi (opredelenie interpretatsii znaka) (On links between cognitive science and semiotics (the definition of sign interpretant)) // Yazyk i kul'tura. Fakty i tsennosti. M.: Yazyki slavyanskoy kul'tury publ., 2001. P. 283-291. (In Russian).

3. Kubryakova E. S. Chasti rechi v onomasiologicheskom osveshchenii (Parts of speech in onomasiological viewpoint). M.: Nauka publ., 1978. 114 p. (In Russian). 
4. Pozdnyakova E. M. Kategoriya imeni deyatelya i puti ee sinkhronnogo razvitiya v kognitivnom i nominativnom aspekte: $\mathrm{Na}$ materiale angliiskogo yazyka (The category of name in person's activity and the ways of its synchronic development in cognitive and nominative aspects on the material of the English language): thesis. Moscow, 1999. (In Russian).

5. Rakhilina E. V. Kognitivnyi analiz predmetnykh imen: ot sochetaemosti k semantike (Cognitive analysis of object names: from lexical combination to semantics): abstract of thesis. Moscow, 1999. (In Russian).

6. Ryabko O. P. Anglo-latinsko-russkii botanicheskii slovar' (English-Latin-Russian botanical dictionary). Rostov-on-Don: RSU publ., 1996, 663 p. (In Russian).

7. Ryabko O. P. Prostranstvenno-vremennoi kontinuum obsekta kognitivnykh protsessov nominatsii (Space-time continuum of the object in cognitive process of nomination) // Vesnik Volgogradskogo gosudarstvennogo universiteta. Issue 2. Linguistics. 2016. Vol. 15. No. 4. P. 190-196. (In Russian).

8. Fillmore Ch. J. Osnovnye problemy leksicheskoi semantiki (The main problems of lexical semantics) // Novoe $\mathrm{V}$ zarubezhnoi lingvistike. 1983. Issue. 11. P. 74-112. (In Russian).

9. Fillmore Ch. J. The Case for Case // Universals in Linguistics theory / ed. E. Bach, R. Harns. L., 1968. P. 1-88.

10. The Oxford English Dictionary. Oxford, 1993. Vol. 1-11. Electronic data. URL: https://www.oxforddictionaries.com/ (Accessed: 21.09.2019).

\section{Сведения об авторе}

Рябко Ольга Павловна - доктор филологических наук, профессор кафедры английского языка гуманитарных факультетов Южного федерального университета (Ростов-на-Дону) / o.ryabko@yandex.ru

\section{Information about the author}

Ryabko Olga - Doctor of Philology, Professor, Chair of English Language for Faculties of Humanities, Southern federal University (Rostov-on-Don)/ o.ryabko@yandex.ru 